LA-UR= $=9-34$

Title:

OPTICAL, RADIO AND X-RAY RADIATION OF RED SPRITES PRODUCED BY RUNAWAY AIR BREAKDOWN

Author(s):

Vyacheslav Yukhimuk

Robert Roussel-Dupre

Eugene Symbalisty

Yuri Taranenko

Submitted to:

XXIII ICPIG

July 17-22, 1997

Toulouse, France

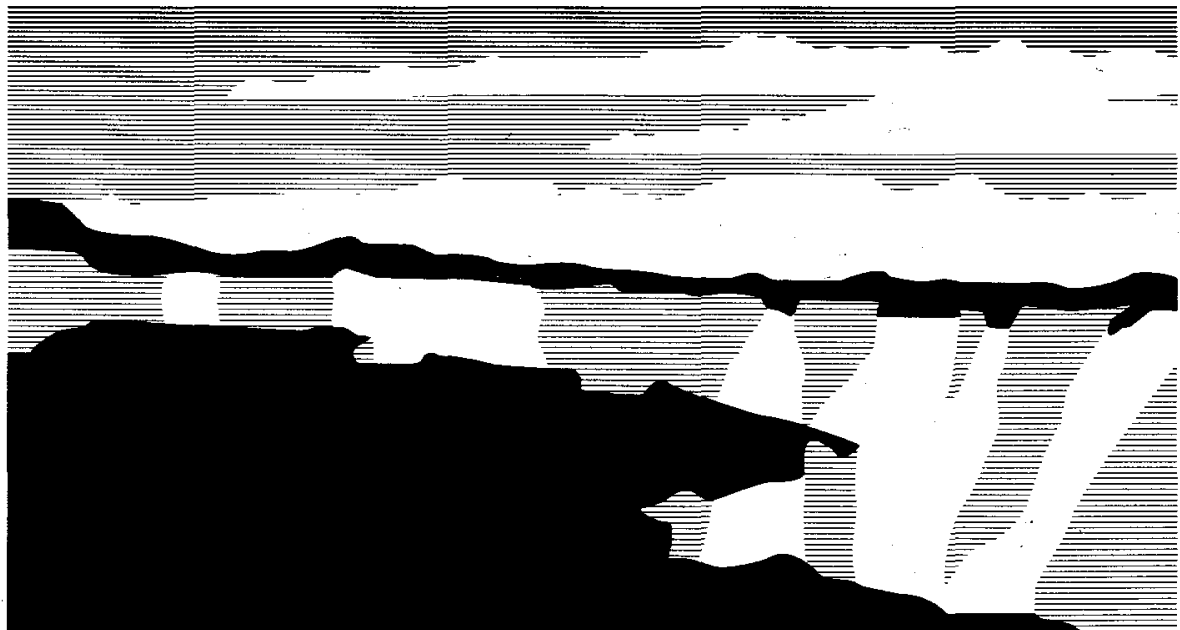

NATIONAL LABORATORY

Los Alamos National Laboratory, an affirmative action/equal opportunity employer, is operated by the University of California for the U.S. Department of Energy under contract W-7405-ENG-36. By acceptance of this article, the publisher recognizes that the U.S. Government retains a nonexclusive, royalty-free license to publish or reproduce the published form of this contribution, or to allow others to do so, for U.S. Government purposes. The Los Alamos National Laboratory requests that the publisher identify this article as work performed under the auspices of the U.S. Department of Energy. 


\section{DISCLAIMER}

This report was prepared as an account of work sponsored by an agency of the United States Government. Neither the United States Government nor any agency thereof, nor any of their employees, make any warranty, express or implied, or assumes any legal liability or responsibility for the accuracy, completeness, or usefulness of any information, apparatus, product, or process disclosed, or represents that its use would not infringe privately owned rights. Reference herein to any specific commercial product, process, or service by trade name, trademark, manufacturer, or otherwise does not necessarily constitute or imply its endorsement, recommendation, or favoring by the United States Government or any agency thereof. The views and opinions of authors expressed herein do not necessarily state or reflect those of the United States Government or any agency thereof. 


\section{DISCLAMMER}

Portions of this document may be illegible in electronic image products. Images are produced from the best available original document. 


$$
\begin{aligned}
& \text { CONF-970724--5 } \\
& L A-U R--97-344
\end{aligned}
$$

\title{
Optical, radio and X-ray radiation of Red Sprites produced by runaway air breakdown
}

\author{
Vyacheslav Yukhimuk, Robert Roussel-Dupré, Eugene Symbalisty, and Yuri Taranenko \\ (Space and Atmospheric Sciences Group, MS D466, Los Alamos National Laboratory, Los Alamos, NM)
}

\section{Introduction}

We use the runaway air breakdown model of upward discharges to calculate optical, radio, and $\mathrm{X}$-ray radiation generated by red sprites. Red sprites are high altitude (up to $90 \mathrm{~km}$ ) lightning discharges. Aircraft based observations [1] show that sprites are predominantly red in color at altitudes above $-55 \mathrm{~km}$ with faint blue tendrils, which extend downward to an altitude of $40 \mathrm{~km}$; the duration of a single sprite is less than $17 \mathrm{~ms}$, their maximum brightness is about $600 \mathrm{kR}$, and estimated total optical energy is about $1-5 \mathrm{~kJ}$ per event. The ground based observations show similar results, and provide some additional information on spatial and temporal structure of sprites [2], and on sprite locations [3]. One difference between aircraft and ground-based observations is that blue tendrils are rarely observed from the ground. Sprites usually occur above the anvils of large mesoscale convective systems and correlate with strong positive cloud to ground discharge [4]. Upward discharges are the most probable source of $\mathrm{X}$-ray emission observed above large thunderstorm complexes by the Compton Gamma-ray Observatory [5]. To escape the atmosphere these $\gamma$-rays must originate above $25 \mathrm{~km}$ altitude. Red sprites are usually observed at altitudes higher than $50 \mathrm{~km}$, and are therefore a likely source of this $\mathrm{x}$-ray emission.

\section{Theoretical results}

We compute optical, radio and gamma-ray emissions caused by electrical discharges propagating upward in upper atmosphere. The results of the kinetic theory for runaway air breakdown [6] are used in our numerical calculations. We use the air fluorescence efficiencies measured by Davidson and O'Neil [7], and Mitchell [8] to calculate optical emissions. The spatial and temporal distribution of the number density and velocity of charged particles, from computer simulations, allow us to reproduce the corresponding distribution of optical emissions in space and time. We use extinction coefficients measured by Guttman [9] to calculate the atmospheric attenuation of optical emissions. The maximum intensity of optical emission calculated over $17 \mathrm{~ms}$ (corresponding to one camera frame) is $647 \mathrm{kR}$. Red emission of $1 \mathrm{P} \mathrm{N}_{2}$ predominates at altitudes higher than $55 \mathrm{~km}$. At altitudes lower than $55 \mathrm{~km}$ blue emission of $2 \mathrm{P} \quad \mathrm{N}_{2}$ and $1 \mathrm{~N} \quad \mathrm{~N}_{2}+$ predominates. We also calculate the radio emissions caused by the upward propagating discharge by using the distribution of electrical current density and charged particle number density in space and time, taken from the numerical simulations of runaway air breakdown.

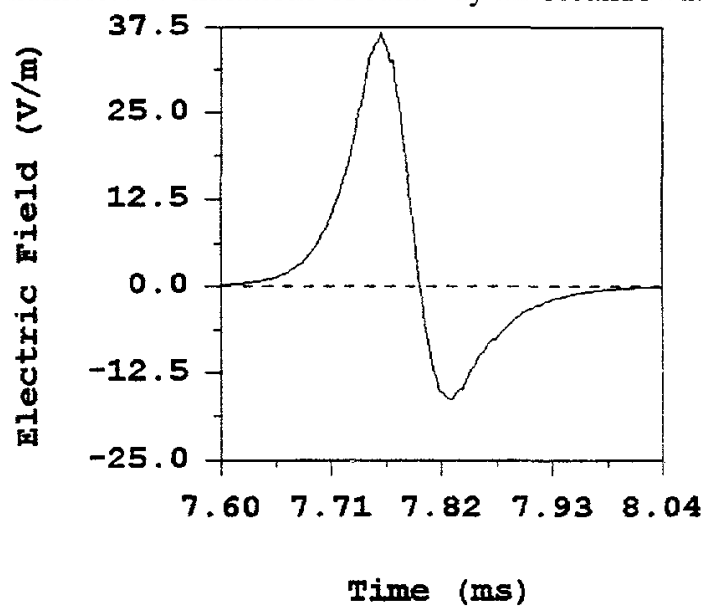

Fig. 1

The electric field of electromagnetic radiation as a function of time for an observer at altitude 80 $\mathrm{km}$ and $50 \mathrm{~km}$ from the center of the discharge is shown in Fig. 1. The maximum electric field amplitude is $37 \mathrm{~V} / \mathrm{m}$. Our results show that the radio emission of upward discharges is comparable with the radio emission of regular lightning. Therefore it is reasonable to conclude that ionospheric phenomena usually associated with radio emission of regular lightning such as ionospheric heating and glowing, lower-hybrid wave generation, explosive spread $\mathrm{F}$ and others can be caused by the radio emissions of upward discharges as well. Given the distribution of velocity and number density of relativistic 
electrons in space and time we compute the spatial and temporal distribution of gamma-ray flux caused by the upward propagating discharge. In our calculations we use the emissivities calculated by Roussel-Dupré et al., [6] based on the Bethe-Heitler doubly differential cross section for bremsstrahlung emission by a relativistic electron. We take into account gamma-ray photons with energy $\mathrm{E}>30 \mathrm{keV}$.

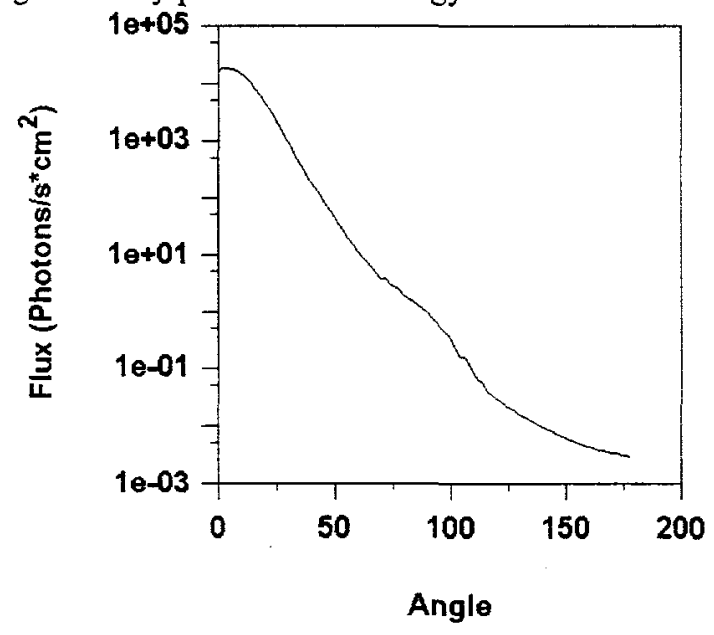

Fig. 2

The gamma-ray flux angular distribution at 1000 $\mathrm{km}$ from the discharge center is shown in Fig. 2.

\section{Discussion and conclusion}

We have compared our theoretical results for optical emissions with observations $[1,2,3]$. The computed intensity is in excellent agreement with the results of observations [1] measured from aircraft. The peak value measured by Sentman et al. [1], is about $600 \mathrm{kR}$, which is close to our computed peak value: $647 \mathrm{kR}$. Our calculations show the presence of visible blue emission at the bottom of the red sprite (blue tendril), which extends downward as low as $40 \mathrm{~km}$. In this case, the blue tendril is visible only from high-altitude platforms $(h \sim 11 \mathrm{~km})$, and becomes invisible from low-altitude because of Rayleigh scattering and scattering from aerosols. This result is in agreement with ground-based observations of red sprites which show no blue tendril for distant sprites.

The computed values of the gamma-ray flux are in agreement with observational results reported by Fishman et al., [5]. As one can see in Fig. 2, the gamma-ray flux depends significantly on the angle of observation. For an observation angle of $90^{\circ}$ the computed flux value is about 0.8 photons $/ \mathrm{s} \times \mathrm{cm}^{2}$, for an angle near $0^{\circ}$ the flux exceeds $10^{4}$ photons $/ \mathrm{s} \times \mathrm{cm}^{2}$. The measured gamma ray flux [5] is about 100 photons $/ \mathrm{s} \times \mathrm{cm}^{2}$. We have calculated the gamma-ray flux without taking into account scattering by air. The scattering will lead to increasing the duration of the pulse and simultaneously decreasing the peak flux value. Our simulation shows that an upward discharge has a tendency to produce several short (with duration about 0.1-0.5 ms) gamma-ray pulses with time separation about $0.1-1 \mathrm{~ms}$. These pulses could appear to an observer as one gamma-ray burst with duration 1-3 ms as a result of gamma-ray scattering. Indeed, such fine structure of the gamma-ray burst was observed by [5], and gamma-ray pulses with duration between 1-3 ms usually had multiple peaks.

In conclusion we note that the runaway air breakdown theory explains $\gamma$-ray emissions above thunderstorms and the blue tendrils of sprites; two phenomena that can not be explained by any other model of upward discharges.

\section{References}

[1] D. D. Sentman, E. M. Wescott, D. L. Osborne, D. L. Hampton, and M. J. Heavner: Geophys. Res. Let., 22 (1995) 1205

[2] J. R. Winckler, W. A. Lyons, T. E. Nelson, and R. J. Nemzek: J. Geophys. Res. 101 (1996) 6997

[3] W. A. Lyons: J. Geophys. Res., 101 (1996) 29641

[4] Boccippio, D. J., E. R. Williams, S. J. Heckman, W. A. Lyons, I. T. Baker, and R. Boldi: Science, 269 (1995) 1088

[5] Fishman, G. J., P. N. Bhat, R. Mallozzi, J. M. Horack, T. Koshut, C. Kouvelioutou, G. N. Pendleton, C. A. Meegan, R. B. Wilson, W. S. Paciesas, S. J. Goodman, and H. J. Christian: Science, 264 (1994) 1313

[6] R. A. Roussel-Dupré, A. V. Gurevich, T. Tunnell, G. M. Milikh: Phys. Rev., 49 (1994) 2257

[7] G. Davidson and R. O'Neil: J. Chem. Phys., 41, 12 (1964) 3946

[8] K. B. Mitchell: J. Chem. Phys., 53, 5 (1970) 1795

[9] A. Guttman: Appl. Opt. 7, 12 (1968) 2377 